Revista

Ibero-Americana

de Estratégıa

ADOÇÃO DE PROCEDIMENTOS INTERNACIONAIS, DO PROCESSO DE BOLONHA, POR UMA UNIVERSIDADE NACIONAL: UM ESTUDO DE CASO

THE ADOPTION OF INTERNATIONAL PROCEEDURES, THE BOLOGNA PROCESS, BY A LOCAL UNIVERSITY: A CASE STUDY AT UNITAU

PROCEDIMIENTOS DE ADOPCIÓN INTERNACIONAL, EL PROCESO DE BOLONIA, POR UNA UNIVERSIDAD NACIONAL: UN ESTUDIO DE CASO

Edson Aparecida de Araujo Querido Oliveira

Doutor em Organização Industrial pelo Instituto Tecnológico de Aeronáutica - ITA

Pró-reitor de Pesquisa e Pós-graduação da Universidade de Taubaté - UNITAU

E-mail: edsonaaqo@gmail.com (Brasil)

Leonardo de Almeida Teixeira

MBA pela Fundação Getúlio Vargas - FGV

Professor do Grupo IBMEC

E-mail: teixeira_leonardo@yahoo.com.br (Brasil)

Elvira Aparecida Simões de Araujo

Doutora em Educação pela Universidade Estadual de Campinas - UNICAMP

Professora da Universidade de Taubaté - UNITAU

E-mail: elvirasaraujo@gmail.com (Brasil) 
Adoção de Procedimentos Internacionais, do Processo de Bolonha, por uma Universidade Nacional: Um Estudo de Caso

\title{
ADOÇÃO DE PROCEDIMENTOS INTERNACIONAIS, DO PROCESSO DE BOLONHA, POR UMA UNIVERSIDADE NACIONAL: UM ESTUDO DE CASO
}

\section{RESUMO}

Este trabalho tem o objetivo de discutir o processo de internacionalização das IES, com base no Processo de Bolonha. Para isso, realizou-se um estudo exploratório sobre internacionalização e o Processo de Bolonha, visando identificar os entraves na aplicação de um modelo de internacionalização de uma IES, o Processo de Bolonha, no curso de Administração, em uma Instituição local, a UNITAU. Essa IES está localizada no Vale do Paraíba Paulista, uma região estratégica e de grande crescimento no país. Trata-se, portanto, de uma região onde a educação e a disponibilidade de mão de obra qualificada são fundamentais para o desenvolvimento regional. O trabalho consiste num estudo de caso, no qual são analisadas as particularidades da legislação brasileira sobre educação (LDB), do modelo europeu e da instituição objeto de estudo. Os resultados apresentam os estágios atuais das linhas de ação que direcionam a aplicação do modelo europeu, na Universidade de Taubaté. As conclusões consideram a convergência do Processo de Bolonha com as diretrizes da educação superior brasileira e apontam algumas dificuldades e oportunidades que podem ser consideradas no caso da implantação de um modelo de internacionalização, na IES.

Palavras-chave: Gestão; Internacionalização; Instituições de Ensino Superior; Educação; Processo de Bolonha.

\section{THE ADOPTION OF INTERNATIONAL PROCEEDURES, THE BOLOGNA PROCESS, BY A LOCAL UNIVERSITY: A CASE STUDY AT UNITAU}

\begin{abstract}
This paper aims to discuss the process of internationalization of the HEI, based on the Bologna Process. An exploratory study was made to identify barriers for the internationalization of a local institution: The University of Taubate. The main topics were the internationalization of the firm and the Bologna Process. This HEI is located in the Vale Paraíba Paulista, a growing and strategic region in Brazilian soil. Education and skilled labor are key elements to regional development. The essay consists of a case study. Particularities from the Brazilian Higher Education System and the European Model are analyzed. They are combined with the Institution's policies. The results show the current stage of the action lines that direct the application of the European model, at the University of Taubate. The conclusions consider the convergence of the Bologna Process with the guidelines of the Brazilian higher education policies, and point out some difficulties and opportunities that may be considered if the HEI decides to adopt an internationalization model.
\end{abstract}

Keywords: Management; Internationalization of the Firms; Higher Education Institutions; Education; The Bologna Process. 
Edson Aparecida de Araujo Querido Oliveira, Leonardo de Almeida Teixeira \& Elvira Aparecida Simões de Araujo

\section{PROCEDIMIENTOS DE ADOPCIÓN INTERNACIONAL, EL PROCESO DE BOLONIA, POR UNA UNIVERSIDAD NACIONAL: UN ESTUDIO DE CASO}

\section{RESUMEN}

Este trabajo tiene como objetivo analizar el proceso de internacionalización de las IES, con base en el Proceso de Bolonia. Para ello, llevamos a cabo un estudio exploratorio sobre la internacionalización y el Proceso de Bolonia, para identificar obstáculos en la implementación de un modelo de internacionalización de una IES, el Proceso de Bolonia, en el curso de la administración, institución en su lugar, UNITAU. Este IES se encuentra en Vale do Paraíba Paulista, una región estratégica de gran crecimiento en el país. Es, por lo tanto, una región donde la educación y la disponibilidad de mano de obra calificada son clave para el desarrollo regional. El trabajo es un estudio de caso que analiza las particularidades de la legislación brasileña sobre la educación (LDB), el modelo europeo de la institución y objeto de estudio. Los resultados muestran el estado actual de las líneas de actuación que orientan la aplicación del modelo europeo, la Universidad de Taubaté. Las conclusiones considerar la convergencia del proceso de Bolonia con las directrices de la educación superior brasileña y señalar algunas dificultades y oportunidades que se pueden considerar en el caso de la implementación de un modelo de internacionalización de las IES.

Palabras-clave: Gestión; Internacionalización; Instituciones de Educación Superior; Proceso de Bolonia. 
Adoção de Procedimentos Internacionais, do Processo de Bolonha, por uma Universidade Nacional: Um Estudo de Caso

\section{INTRODUÇÃO}

Uma breve retrospectiva histórica nos mostra que a origem das Universidades tem forte influência internacional. Professores provenientes de várias partes do mundo foram recrutados para iniciar as primeiras atividades de ensino e pesquisa. Dessa forma, pode-se dizer que a internacionalização é um processo que nos remete à análise das fundações das antigas Universidades de Paris e Bolonha no século XIII.

Segundo Miura (2006), o estudo da internacionalização do ensino superior tem se intensificado nas últimas décadas, devido aos impactos da globalização na educação.

De acordo com Stalivvieri (2004), frente ao acelerado processo de internacionalização, especialmente nas últimas duas décadas, mais efetivamente nos níveis científicos e tecnológicos, as universidades buscam espaço diante desse novo panorama que se apresenta. Esse processo passa a ser até uma questão de sobrevivência, ou seja, torna-se necessário internacionalizar para poder competir em níveis de igualdade com as melhores instituições de ensino superior, nacionais e estrangeiras.

Embora estejam intimamente relacionados e frequentemente usados como sinônimos, os termos globalização e internacionalização do ensino superior referem-se a dois fenômenos distintos. Globalização normalmente faz referência "às grandes tendências econômicas, tecnológicas e científicas que afetam diretamente o ensino superior e são largamente inevitável no mundo contemporâneo". (KNIGHT, 2004, p. 8)

A internacionalização, por outro lado, tem mais a ver com as "políticas específicas e programas desenvolvidos pelos governos, sistemas acadêmicos, instituições e mesmo departamentos isolados, para lidar com a globalização". (ALTBACH, 2006, p. 123)

Com o intuito de resgatar a tradição europeia entre os principais centros de ensino no mundo, no final dos anos 90, ocorreu a assinatura do Processo de Bolonha (BOLONHA, 1999). Esse pode ser considerado um marco para a definição de padrões internacionais a serem adotados pelas instituições europeias. Uma tentativa de adequação dos diversos critérios de educação existentes nos países europeus ao novo milênio.

Enquanto isso, no Brasil, o final dos anos 90 pode ser caracterizado pela concretização da economia brasileira, que se tornou ainda mais internacionalizada, com a implantação do processo de abertura comercial, durante a última década do século.

Considerando-se o processo de internacionalização da economia brasileira, e a transformação nas diretrizes da educação superior do país, o presente trabalho objetiva discutir o 
Edson Aparecida de Araujo Querido Oliveira, Leonardo de Almeida Teixeira \& Elvira Aparecida Simões de Araujo

processo de internacionalização das IES, com base no Processo de Bolonha. Pretende-se, também, discutir o processo de internacionalização das organizações de uma maneira geral; caracterizar o processo de internacionalização das IES; identificar os entraves para a implantação do Processo de Bolonha, nos cursos de Administração, em uma IES local; e identificar vantagens e dificuldades na adoção de uma estratégia internacional, por parte de uma IES.

O presente estudo não pretende analisar internacionalização com a ótica do fluxo financeiro internacional. E sim os processos que podem ser adotados em uma IES local, para fazer frente às exigências internacionais no que se refere ao estado da arte em educação superior.

\subsection{ESTRATÉGIA GLOBAL E INTERNACIONALIZAÇÃO DAS EMPRESAS}

De acordo com Porter (1996), a essência da estratégia está no desempenho de atividades de maneira distinta dos concorrentes. Peng (2011) define estratégia global como a estratégia das empresas ao redor do globo, que está relacionada com a teoria das organizações de como obter sucesso frente à concorrência. Essa definição incorpora tanto a estratégia internacional (crossborder) quanto a local (doméstica), contribuindo para uma tendência de dificuldade de distinção entre internacional e local.

Prahalad e Conner (1996) avaliam a perspectiva da estratégia com base nos recursos internos. Os autores afirmam que a essência dessa perspectiva está no conhecimento de cada empresa. As próprias competências essenciais são geradas com base nesse conhecimento e são fontes de vantagem competitiva.

Peng et al. (2009) apontam que, tanto a perspectiva com base na indústria, quanto a com base nos recursos precisam ser consideradas. Os autores apontam a importância de se somar a essas perspectivas a base institucional. North (1990 apud PENG, 2011) utiliza a metáfora "as regras do jogo", tratando do tema, e define instituições como as restrições concebidas pelos seres humanos, as quais estruturam a interação entre eles.

As instituições variam muito de país para país, e, principalmente no caso dos países emergentes e subdesenvolvidos, elas precisam ser avaliadas à parte, uma vez que podem ser responsáveis diretas pela má adaptação da empresa em uma nação. Ao tratar as instituições como variáveis independentes, uma visão estratégica, com base nas instituições, foca-se na interação dinâmica entre instituições e organizações, e considera decisões estratégicas como um produto de tal interação. (PENG, 2011)

Revista Ibero-Americana de Estratégia - RIAE, São Paulo, v. 11, n. 3, p. 263-288, set./dez. 2012. 
Adoção de Procedimentos Internacionais, do Processo de Bolonha, por uma Universidade Nacional: Um Estudo de Caso

Johanson e Vahlne (2009), criadores do modelo desenvolvido na universidade de Uppsala, Suécia, em 1977, e que se tornou referência no assunto, definem internacionalização como o processo de desenvolvimento de redes multilaterais. Estar de fora de uma rede de relacionamentos (outsidership) inviabiliza o desenvolvimento de negócios. O processo de aprendizagem e confiança e a construção de um comprometimento estão, diretamente, relacionados ao sucesso do negócio.

Em uma ótica econômica, Dunning (1972) insere o uso do conceito de internacionalização, como um complemento ao seus estudos (The Ownership and Location Paradigm), publicado desde o início dos anos 1950, criando então o tripé que explicaria o escopo e a geografia de atividades que geram valor, em empresas multinacionais Norte-americanas.

O autor, que pode ser considerado um dos pioneiros no tema, apresenta, já no século XXI (2001), a relevância de seu paradigma eclético da produção internacional (OLI Paradigm of International Production), uma vez que este, mesmo após mais de trinta anos de sua criação, ainda pode ser considerado uma ferramenta robusta e atual para a análise das atividades globais das grandes empresas.

Buckley e Ghauri (2004) afirmam que o processo de desenvolvimento de uma oportunidade é similar ao processo de internacionalização. É uma questão de processos inter-relacionados de desenvolvimento e comprometimento a uma oportunidade. As empresas precisam aprender a criar e reforçar relações para poder explorar oportunidades.

A saturação dos mercados domésticos, o número crescente de competidores que se posicionam em mercados internacionais de uma maneira contundente, entre outros, fazem com que a seleção de mercados internacionais se converta em uma das decisões determinantes na internacionalização das empresas. (DOUGLAS; CRAIG, 1992)

Alguns autores propuseram que a internacionalização poderia ter motivações estratégicas, como, por exemplo, retaliar ações prévias dos competidores ou posicionar-se em mercados potenciais (MADSEN, 1998), bem como reduzir a exposição a fornecedores ou mercados (PORTER, 1980), ou, ainda, buscar ativamente tecnologia e conhecimento.

Welch e Luostarinen (1988) comentam que o envolvimento internacional é mais forte quando os principais decisores participam ativamente das decisões da empresa. Os autores afirmam, também, que a capacidade da empresa de marcar presença em diferentes regiões geográficas ou mercados estrangeiros deve vir acompanhada de uma aptidão para estabelecer relacionamentos profundos e duradouros com parceiros locais.

Revista Ibero-Americana de Estratégia - RIAE, São Paulo, v. 11, n. 3, p. 263-288, set./dez. 2012. 
Edson Aparecida de Araujo Querido Oliveira, Leonardo de Almeida Teixeira \& Elvira Aparecida

Simões de Araujo

\subsection{INTERNACIONALIZAÇÃO DAS IES}

A dimensão internacional da educação superior foi um tópico de significativo interesse e debate na primeira década do século XXI (KNIGHT, 2003). Fatores como o desenvolvimento de novas ferramentas de comunicação e serviços tecnológicos; o aumento da mobilidade internacional do trabalho; a maior ênfase na economia de mercado e na liberalização comercial; o foco na sociedade do conhecimento, entre outros, colaboram para a caracterização do ambiente em que as IES estão inseridas. (KNIGHT, 2005)

A globalização e seus efeitos estão além do controle de qualquer ator ou conjunto de atores. A internacionalização, no entanto, pode ser vista como uma estratégia para as sociedades e instituições para responder às muitas exigências que lhes são impingidas pela globalização e como um caminho, para o ensino superior, de preparar os indivíduos para o engajamento em um mundo globalizado. (ALTBACH et al., 2009)

A internacionalização tem sido concebida em muitos setores como um "processo de integração de uma dimensão internacional, intercultural, ou global, necessários para a entrega de uma educação de nível superior" (KNIGHT, 2003, p. 2). Esse processo consiste, basicamente, em duas principais esferas de ação, comumente caracterizadas como "internacionalização em casa" e "internacionalização no estrangeiro". (KNIGHT, 2004)

A internacionalização em casa normalmente consiste em estratégias e abordagens destinadas a injetar uma dimensão internacional no próprio campus. Isso significa incluir as perspectivas globais e comparativas no currículo, além do recrutamento de estudantes, acadêmicos e professores internacionais, tirando proveito de suas presenças no campus. Internacionalização no estrangeiro, por outro lado, inclui a projeção de atuação de uma instituição e de seus stakeholders no mundo.

A internacionalização do ensino superior é notável para as múltiplas formas em que se manifestou em todo o mundo. Apesar de cada contexto local, nacional e regional apresentar características únicas, algumas tendências gerais podem ser identificadas em nível mundial.

Esses desenvolvimentos incluem a mobilidade das pessoas, programas e instituições; a crescente importância da pesquisa colaborativa; a evolução dos currículos, bem como as abordagens para o ensino e aprendizagem; um sentido cada vez mais elevado de interconexão da empresa de ensino superior em todo o mundo; e a crescente penetração do fenômeno da internacionalização nas instituições e sistemas mais amplos de educação superior. (ALTBACH; KNIGHT, 2007)

As características da educação estão intimamente imbricadas com o processo de globalização e com as determinações oriundas de organismos internacionais multilaterais. O Estado 
Adoção de Procedimentos Internacionais, do Processo de Bolonha, por uma Universidade Nacional: Um Estudo de Caso

avaliativo adquire a conotação de avaliação em todos os aspectos da realidade educacional e em todos os níveis do sistema.

Entretanto, é no sistema de ensino superior que se verifica o maior impacto. Isso porque a globalização considera, como um dos principais valores, o conhecimento, e, neste, o advindo de patamares superiores, nos quais, a busca de educação e certificação continuada se faz presente. A universidade adquire um valor máximo e a concepção de liberdade acadêmica, símbolo da intocabilidade do ensino superior, passa a sofrer impacto. (MOROSINI, 2010)

O processo de massificação do ensino superior (a que não são alheios nem a heterogeneidade que passou a caracterizar a população estudantil, nem o aumento do número de docentes), associado aos desafios de criatividade, inovação e qualidade "impostos" pela Sociedade do Conhecimento, produziu um impacto muito grande nas instituições universitárias, no modelo de ensino aprendizagem vigente e no perfil desejável do professor universitário. (MORGADO, 2006)

Em termos de ensino aprendizagem, a ênfase deixa de ser colocada no ensino e passa a incidir na aprendizagem, ocupando esta o núcleo do processo de formação; a produção de conhecimento passa a ser dirigida para as aplicações práticas, voltando, assim, "um pouco as costas ao conhecimento pelo conhecimento". (QUINTANILHA, 2003, p. 24)

\subsection{SOBRE A EDUCAÇÃO SUPERIOR}

O processo de formação humana diz respeito ao indivíduo e às suas relações com a sociedade. É contínuo, e, portanto, jamais concluído. As necessidades, de curto prazo, do ser humano demandam uma formação que atenda o imediato, mas que, também, ultrapasse-o amplamente. A educação tem um sentido prospectivo; mesmo quando lida com o presente, remetese à construção do que ainda não existe. (DIAS SOBRINHO, 2010)

A escola que preparou o trabalhador para um processo de trabalho assentado no paradigma industrial, caracterizado pela rígida separação entre a concepção do trabalho e a execução padronizada das tarefas, deixou de atender às demandas de uma nova etapa do capital.

A escola foi criticada e responsabilizada pelo despreparo dos alunos ao término dos estudos, pela desvinculação, dos conteúdos ensinados, das novas demandas oriundas do mundo do trabalho. (MAUÉS; CAMARGO, 2008)

Da mesma forma, os professores sofreram profundas críticas, havendo uma espécie de responsabilização dos docentes pelo "fracasso" escolar. A formação desses profissionais passou a 
Edson Aparecida de Araujo Querido Oliveira, Leonardo de Almeida Teixeira \& Elvira Aparecida Simões de Araujo

ser vista como muito "teórica", desvinculada de uma prática efetiva e afastada das demandas das escolas e da sociedade. (MAUÉS, 2006)

As reformas, no âmbito da educação, correspondem a uma resposta política a situações de desequilíbrios. As reformas educacionais se tornam necessárias quando surgem ou se agudizam problemas, nas estruturas econômicas, sociais e políticas, que requerem soluções urgentes. Em se tratando de educação superior, ela também precisa ser repensada, de modo que possa promover mudanças em suas estruturas internas e transformações, nas suas relações com a sociedade e com o estado. (DIAS SOBRINHO, 2005)

Mancebo (2008) indica que, no campo educacional, com a adoção da pauta neoliberal, estabeleceu-se, em todos os países do continente (América do Sul), uma série de medidas, enfeixadas ou não, sob a denominação de reformas, que, (p. 58) “(...) para além das especificidades locais, evidenciaram uma profunda redefinição do papel do Estado na sua relação com a educação".

Para Morosini (p.287, 2008), “as IES pautavam-se em uma concepção, de modelos universitários mistos, de origem napoleônica e/ou humboldtiana, nos quais a figura de universidade era a regra e, destacadamente, a da universidade pública". Segundo a autora, a criação da LDB n ${ }^{\circ}$ 9.394/96 (Lei de Diretrizes e Bases da Educação Nacional), de 20 de dezembro de 1996, foi um dos marcos normativos dessa mudança.

Atualmente, o sistema tornou-se mais complexo e diversificado, pendendo para um modelo híbrido, heterônimo e neoprofissional (SGUISSARDI, 2003), em um sistema de educação superior caracterizado pela: concentração em regiões desenvolvidas do país; expansão; privatização; centralização da avaliação de IES e/ou de cursos; e, mais recentemente, pela internacionalização da educação superior.

\subsection{O MODELO PROPOSTO: O PROCESSO DE BOLONHA}

O objetivo geral do Processo de Bolonha é criar um Espaço Europeu de Educação Superior (EEES) que promova a mobilidade; atraia estudantes e professores (staff) da Europa e de outras regiões do mundo; e que seja competitivo internacionalmente. Pretende-se fazer isso facilitando-se a comparabilidade e a compatibilidade entre os diversos sistemas e instituições educacionais da Europa e elevando sua qualidade. (BOLONHA, 1999)

Atualmente, são 47 os países que participam do Processo de Bolonha. Todos são partidários da Convenção Cultural Europeia e comprometidos com os objetivos do EEES. Iniciou-se em 1999, com a assinatura da Declaração de Bolonha, e continuou evoluindo, desde então.

Revista Ibero-Americana de Estratégia - RIAE, São Paulo, v. 11, n. 3, p. 263-288, set./dez. 2012. 
Adoção de Procedimentos Internacionais, do Processo de Bolonha, por uma Universidade Nacional: Um Estudo de Caso

Dentre as prioridades para o novo decênio, foram criados sete grupos de trabalho para tópicos considerados de extrema relevância. São eles: a dimensão social; o quadro de qualificações; a abertura internacional; a mobilidade; o reconhecimento dos diplomas; os relatórios de implementação do Processo; e os mecanismos de transparência.

\section{METODOLOGIA}

No presente estudo, utilizou-se, como referência, o modelo proposto no Processo de Bolonha, sendo que as etapas serão definidas com base em documentos publicados oficialmente pelos participantes do Processo de Bolonha. Para isso, foram comparados o estágio atual das principais linhas de ação, presentes no modelo europeu, na IES estudada.

Em relação aos procedimentos técnicos, trata-se de um estudo de caso, com base em pesquisa bibliográfica e documental. Envolveu um profundo estudo que permitiu um amplo e detalhado conhecimento sobre aquilo que se pretendia na pesquisa, sob o ponto de vista de uma única IES, objeto de estudo.

Os principais documentos que foram analisados, para a elaboração do presente trabalho, podem ser divididos em dois grupos: os documentos referentes ao Processo de Bolonha; e os documentos referentes à Universidade de Taubaté.

Os primeiros foram obtidos, principalmente, por meio do website oficial de Bolonha, bem como de websites das instituições pertencentes à Bolonha. A transparência exigida e almejada pelo Processo facilitou o acesso à informação.

No caso da UNITAU, os documentos utilizados foram os publicados pelos conselhos Administrativo (CONSAD), Universitário (CONSUNI) e de Ensino e Pesquisa (CONSEP). Ademais, foram utilizados o Plano Diretor Institucional (PDI), o Projeto Pedagógico do curso de Administração, entre outros documentos disponíveis no website da instituição e fornecidos pela direção da instituição.

No presente estudo, a análise de dados realizou-se com base na comparação das linhas de ação propostas pelo modelo de Bolonha, com os documentos oficiais da UNITAU.

A compreensão das particularidades, para a execução de cada uma das linhas de ação do modelo europeu, foi reforçada com a análise dos relatórios de instituições europeias, adeptas ao modelo. Esses relatórios auxiliaram na análise dos dados, pois serviram como uma referência, um benchmarking.

Revista Ibero-Americana de Estratégia - RIAE, São Paulo, v. 11, n. 3, p. 263-288, set./dez. 2012. 
Edson Aparecida de Araujo Querido Oliveira, Leonardo de Almeida Teixeira \& Elvira Aparecida Simões de Araujo

Com o intuito de validar as linhas de ação do modelo europeu, e o estágio atual na UNITAU, foram utilizadas a legislação brasileira (LDB, PNE, entre outros documentos oficiais), e as publicações dos conselhos da Instituição (CONSAD, CONSUNI, CONSEP).

\section{ANÁLISE E DISCUSSÃO DOS RESULTADOS}

\subsection{RESULTADOS}

\section{LINHAS DE AÇÃO 1 E 2: ADOÇÃO DE UM SISTEMA DE GRAUS ACADÊMICOS FACILMENTE LEGÍVEL E COMPARÁVEL; E ADOÇÃO DE UM SISTEMA ASSENTE ESSENCIALMENTE EM DOIS CICLOS.}

Os cursos de graduação da UNITAU já estão passando por uma mudança. Em 2009, foi aprovada a mudança do regime do curso de Administração: de anual a semestral (DELIBERAÇÃO CONSEP N ${ }^{0}$ 096/2009). Essa mudança vai ao encontro das exigências de Bolonha. Apesar do curso ainda funcionar anualmente, a experiência de 2009 demonstra que, em seu ritmo, as mudanças estão acontecendo.

Mais do que isso, a existência do curso em regime semestral, mesmo que com um processo seletivo anual de alunos, demonstra que a organização experimentou uma mudança curricular, e, portanto, está mais preparada para a sua implementação. A partir de 2013, o curso de graduação em administração passará ao regime semestral, em definitivo.

Em relação à duração de cada ciclo, não basta a redução da duração de um curso de 10 semestre para 6 semestres, mediante eliminação de disciplinas. O Processo de Bolonha significa reorganizar o processo formativo em torno de novos valores: as competências, não só os conteúdos; as aprendizagens, não, simplesmente, o ensino; a participação e o envolvimento de todos os agentes implicados, não, apenas, a participação de professores, nas aulas, e de estudantes no estudo e exames.

A própria legislação brasileira sinaliza a importância desse tipo de mudança no processo formativo da educação Superior. O REUNI (DL No 6.096/2007), o qual faz parte do Plano de Desenvolvimento da Educação (PDE), em seus Referenciais Orientadores para os Bacharelados

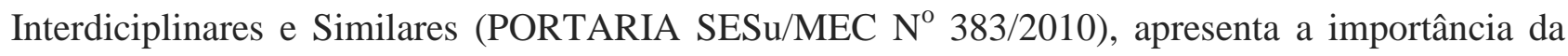
formação de natureza geral, no que corresponde ao primeiro ciclo, e da necessidade da "(...)adoção

Revista Ibero-Americana de Estratégia - RIAE, São Paulo, v. 11, n. 3, p. 263-288, set./dez. 2012. 
Adoção de Procedimentos Internacionais, do Processo de Bolonha, por uma Universidade Nacional: Um Estudo de Caso

de metodologias ativas de ensino e aprendizagem, de maneira a fomentar o desenvolvimento intelectual dos estudantes".

O curso de Mestrado em Gestão e Desenvolvimento Regional pode ser caracterizado como segundo ciclo, no curso de Administração (ECA - Departamento de Economia, Contabilidade e Administração). A duração mínima do curso é de um ano e a máxima de dois anos consecutivos, incluindo a elaboração de Dissertação. (DELIBERAÇÃO CONSEP N ${ }^{0} 173 / 2009$ )

O Quadro de Qualificações, desenvolvido para o Espaço Europeu de Educação Superior EEES (BERGEN, 2005), define, de forma genérica, as competências e habilidades, a serem desenvolvidas, em cada ciclo, no modelo de Bolonha. Suas premissas podem ser usadas como referência à elaboração de uma nova grade curricular, para os cursos de Administração da UNITAU (Bacharelado e Mestrado).

As ferramentas desenvolvidas, ECTS e Suplemento ao Diploma, também permitem que se encare a formação obtida num sentido diferente: a preocupação com o grau acadêmico, o título, será substituída pela preocupação com os conhecimentos e as competências obtidas, verdadeiras razões de ser dos processos de ensino/aprendizagem.

O Quadro 1 apresenta um resumo do diagnóstico do estágio atual das linhas de ação um e dois, do Processo de Bolonha, na UNITAU.

\begin{tabular}{|c|c|}
\hline \multicolumn{2}{|l|}{ Linhas de ação 1 e 2} \\
\hline ítem avaliado & status observações \\
\hline Sistema em 2 ciclos & De acordo com legislação brasileira \\
\hline Regime semestral & Experiência de 2009 \\
\hline Reorganização do processo formativo (competências e habilidades) & Diretrizes Curriculares Nacionais \\
\hline Suplemento ao Diploma & Documento inexistente na IES \\
\hline
\end{tabular}

Quadro 1 - diagnóstico do estágio atual das linhas de ação 1 e 2, na UNITAU.

Legendas para o status: __ aceitável; _ parcialmente aceitável; $\square$ inexistente.

\section{LINHA DE AÇÃO 3: ESTABELECIMENTO E GENERALIZAÇÃO DE UM SISTEMA DE CRÉDITOS ACADÊMICOS (ECTS)}

O ECTS é um sistema de medida do trabalho necessário para que um estudante complete, com êxito, uma determinada unidade curricular (nova designação das cadeiras ou disciplinas).

Revista Ibero-Americana de Estratégia - RIAE, São Paulo, v. 11, n. 3, p. 263-288, set./dez. 2012. 
Edson Aparecida de Araujo Querido Oliveira, Leonardo de Almeida Teixeira \& Elvira Aparecida Simões de Araujo

Um ano curricular (60 ECTS) costuma variar de mil e quinhentas a mil e oitocentas horas, o que significa que cada crédito corresponde a algo entre vinte e cinco e trinta horas de trabalho total do aluno.

O curso de graduação em Administração da UNITAU tem duração de quatro anos, com carga horária mínima de 3.216 horas. (DELIBERAÇÃO CONSEP Nº 096/2009)

O desenvolvimento de um novo programa, para que o curso esteja adequado às normas europeias, exige a implementação de mudanças que incluem a carga horária (presencial, virtual, de estudo/pesquisa, entre outros), os métodos de ensino/aprendizagem (centrado no aluno), e a adequação da estrutura e dos recursos (salas menores, equipadas com recursos tecnológicos), para uma nova realidade.

Sugere-se, com este trabalho, a criação de uma nova grade curricular para a adequação do curso de Administração da UNITAU, tendo como referência algumas instituições europeias que já adotam o Processo de Bolonha e possuem o curso de Administração e o ECTS Users' Guide (EUROPEAN COMMUNITIES, 2009), que é o documento base para a adequação ao sistema de créditos europeu.

No caso do curso de Mestrado, o número mínimo de créditos exigidos para a conclusão é 43. Considerando-se que a duração de um crédito é de 15 horas, totaliza-se uma carga horária mínima de 645 horas. (DELIBERAÇÃO CONSEP Nº 173/2009)

O conceito de créditos e unidades curriculares presentes em Bolonha diferem da realidade brasileira. No entanto, a própria legislação brasileira vem se adaptando às mudanças, pelo menos em relação à educação superior, quando abrem "brechas" a mudanças, desde que estas estejam bem justificadas.

Ademais, as próprias Diretrizes Curriculares Nacionais do Curso de Administração contemplam o desenvolvimento de competências e habilidades $\left(2005\right.$, Art. $\left.4^{\circ}\right)$ e (...) "conteúdos que revelem inter-relações com a realidade nacional e internacional" (2005, Art. $\left.5^{\circ}\right)$.

Pretendendo-se que Bolonha traga inovação às metodologias de ensino, faz-se necessária a criação de um Programa de Formação Avançada de Docentes do Ensino Superior, com base, pelo menos, em três módulos de 50h/a cada:

Docência e Aprendizagem Colaborativa no Ensino Superior - Bolonha: realizar, monitorar e avaliar os processos de estudar, aprender, investigar e inovar;

Tecnologias da Informação e da Comunicação (TIC) no Ensino Superior; e Pedagogia e Desenvolvimento Curricular para o uso das TIC no Ensino Superior.

Revista Ibero-Americana de Estratégia - RIAE, São Paulo, v. 11, n. 3, p. 263-288, set./dez. 2012. 
Adoção de Procedimentos Internacionais, do Processo de Bolonha, por uma Universidade Nacional: Um Estudo de Caso

Esses três módulos podem ser ministrados por representantes de alguma organização europeia, certificada pela ENQA (normalmente uma universidade adepta à Bolonha), ou por algum profissional capacitado para tal.

Os módulos podem ser totalmente, ou parcialmente, presenciais. Estimula-se, também, a promoção de workshops com temas atuais, em relação às novas metodologias de ensinoaprendizagem, focadas no aluno.

O Quadro 2 apresenta um resumo do diagnóstico do estágio atual, da linha de ação três, do Processo de Bolonha, na UNITAU.

\begin{tabular}{|c|c|}
\hline \multicolumn{2}{|l|}{ Linha de ação 3} \\
\hline ítem avaliado & status observações \\
\hline Harmonização com o ECTS & Ferramenta não adotada \\
\hline Duração do curso de Graduação & $3216 \mathrm{~h} / 4$ anos X 4500h/3anos \\
\hline Duração do curso de mestrado & $645 \mathrm{~h} / 2$ anos $\times 3000 \mathrm{~h} / 2$ anos \\
\hline Formação de Docentes para metodologia centrada no aluno & Não existe treinamento para tal \\
\hline Formação de alunos do 10 ano para nova metodologia & Não existe treinamento para tal \\
\hline Promoção de eventos/workshops com temas atuais & Existem tais eventos (SEDUNI etc.) \\
\hline
\end{tabular}

Quadro 2 - diagnóstico do estágio atual da linha de ação 3, na UNITAU.

Legendas para o status: __ aceitável; parcialmente aceitável; __ inexistente.

\section{LINHA DE AÇÃO 4: PROMOÇÃO DA MOBILIDADE}

A UNITAU participou e participa, atualmente, de programas de cooperação internacionais com outras universidades, abrangendo as atividades de pesquisa e de intercâmbio de alunos de graduação. Entre os anos 2006 e 2011, a Instituição firmou convênios de parcerias internacionais com países sul americanos, norte americanos, europeus, asiáticos e africanos.

Em 2009, foi criada a Coordenadoria de Cooperação Internacional da Universidade de Taubaté (DELIBERAÇÃO CONSUNI Nº 021/2009). Esse órgão está vinculado, diretamente, à Reitoria, para assessorá-la na área de cooperação internacional, e promover o intercâmbio acadêmico, cultural e científico com instituições estrangeiras.

A adequação do curso de Administração ao Processo de Bolonha permite o aumento da participação da Instituição em programas de cooperação internacionais, visto que, nesse tipo de programa, a mobilidade caracteriza-se como um dos alicerces do EEES.

Revista Ibero-Americana de Estratégia - RIAE, São Paulo, v. 11, n. 3, p. 263-288, set./dez. 2012. 
Edson Aparecida de Araujo Querido Oliveira, Leonardo de Almeida Teixeira \& Elvira Aparecida Simões de Araujo

Alguns desafios permanecem em relação à mobilidade entre IES. Dentre as grandes preocupações ou principais barreiras, encontram-se a obtenção de vistos e autorizações para trabalho; incentivos financeiros e bolsas; programas conjuntos e currículos flexíveis; e reconhecimento das qualificações.

O Quadro 3 apresenta um resumo do diagnóstico do estágio atual da linha de ação quatro, do Processo de Bolonha, na UNITAU.

\begin{tabular}{|l|l|l|}
\hline Linha de ação 4 & \multicolumn{2}{|l|}{ status observações } \\
ítem avaliado & & existem convênios e intercambistas \\
Mobilidade estudantil na graduação & & existem convênios apenas \\
Mobilidade estudantil no mestrado & & não ocorre \\
\hline Mobilidade internacional de professores & não ocorre \\
Mobilidade de pessoal administrativo & existe a coordenadoria de coop. int. \\
\hline Existência de órgão interno para promoção da mobilidade &
\end{tabular}

Quadro 3 - diagnóstico do estágio atual da linha de ação 4, na UNITAU.

Legendas para o status: __ aceitável; parcialmente aceitável; _ inexistente.

\section{LINHA DE AÇÃO 5: GARANTIA DE QUALIDADE}

Os padrões para a garantia de qualidade na educação superior estão divididos em três partes. A garantia interna de qualidade (primeira parte), a garantia externa de qualidade (segunda parte), e a garantia da qualidade das agências responsáveis pela garantia externa de qualidade (terceira parte). (ENQA, 2005)

Para se adequar às exigências de Bolonha, a preocupação está em atender as duas primeiras partes. A primeira, internamente, e a segunda, com a intervenção de um terceiro (normalmente uma agência certificadora).

Na UNITAU, o processo de avaliação institucional interna existe e é de caráter contínuo e permanente (DELIBERAÇÃO CONSUNI N 009/2009). Em 2010, foi aprovado o Regimento Interno da Comissão Própria de Avaliação - CPA/UNITAU (DELIBERAÇÃO CONSUNI N ${ }^{\circ}$ 039/2010).

Em 2011, foi criada a Comissão Permanente de Avaliação de Desempenho Docente COPADD (DELIBERAÇÃO CONSUNI N 045/2011), que é um órgão complementar da Reitoria,

Revista Ibero-Americana de Estratégia - RIAE, São Paulo, v. 11, n. 3, p. 263-288, set./dez. 2012. 
Adoção de Procedimentos Internacionais, do Processo de Bolonha, por uma Universidade Nacional: Um Estudo de Caso

com atribuição de coordenar e supervisionar o processo de promoção na carreira do magistério superior na Universidade.

Em relação à avaliação externa, a Instituição segue as diretrizes do INEP. Todos os procedimentos internos foram implementados para respeitar a legislação vigente do SINAES (ART. $3^{\mathrm{o}}$ da LEI N $\left.{ }^{\mathrm{o}} 10.861 / 2004\right)$.

No ano de 2007, a UNITAU firmou um convênio com a Det Norske Veritas Certificadora Ltda (DELIBERAÇÃO CONSUNI $\mathrm{N}^{0}$ 002/2007). A implementação de uma certificação internacional de qualidade é uma maneira de se buscar credibilidade internacional nos serviços prestados.

O Quadro 4 apresenta um resumo do estágio atual da linha de ação cinco, na UNITAU.

\begin{tabular}{|c|c|}
\hline \\
\hline \multicolumn{2}{|l|}{ Linha de açáo 5} \\
\hline Existência de órgão interno para promoção da qualidade & CPAIUNITAU \\
\hline Avaliação externa da qualidade & INEP/SINAES/MEC \\
\hline Certificações internacionais de qualidade & Convênio com Bureau Veritas \\
\hline Transparência nas avaliações internas de qualidade & não é percebido internamente \\
\hline
\end{tabular}

Quadro 4 - diagnóstico do estágio atual da linha de ação 5, na UNITAU.

Legendas para o status: __ aceitável; parcialmente aceitável; __ inexistente.

\section{LINHA DE AÇÃO 6: PROMOÇÃO DA EDUCAÇÃO CONTINUADA}

Dentre os principais objetivos estabelecidos para a evolução da educação continuada, encontram-se o reconhecimento da aprendizagem prévia, incluindo a aprendizagem não formal e informal; a criação de cursos mais centrados no aprendizado do aluno; e o estímulo ao acesso à educação superior.

A ênfase na educação continuada exige um maior foco da instituição no que se refere à identificação das necessidades/carências do mercado de trabalho regional/nacional. Já existem diversas atividades de extensão.

No entanto, a demonstração de uma atuação ativa demanda a criação de um centro específico para a educação continuada, que centralize as atividades da instituição que se enquadrem nesta linha de ação. (BOLONHA, 2010)

Revista Ibero-Americana de Estratégia - RIAE, São Paulo, v. 11, n. 3, p. 263-288, set./dez. 2012. 
Edson Aparecida de Araujo Querido Oliveira, Leonardo de Almeida Teixeira \& Elvira Aparecida Simões de Araujo

Tal centro deve interagir constantemente com a comunidade, e informá-la do envolvimento que a IES tem com a sociedade. O resultado, normalmente, consiste na adequação dos programas da instituição, às necessidades do mercado.

Algumas atividades, como cursos de extensão, cursos de pós-graduação de curta duração, cursos de MBA, cursos superiores de tecnólogos, cursos para terceira idade, educação corporativa e cursos de pós-graduação a distância, já são desenvolvidas pela IES.

O Quadro 5 apresenta um resumo da linha de ação seis, na UNITAU.

\begin{tabular}{|l|l|l|}
\hline Linha de ação 6 & \multicolumn{2}{|l|}{ status observações } \\
ítem avaliado & & Reconhecimento de diplomas \\
Reconhecimento da aprendizagem prévia & & curso de extensão, pós, EAD... \\
Adequação de programas às necessidades do mercado & & alguns cursos mais que outros \\
Criação de cursos mais centrados na aprendizagem dos alunos & & educação corporativa, e extensão \\
\hline Estímulo ao acesso à educação superior & & \\
\cline { 2 - 3 } & &
\end{tabular}

Quadro 5 - diagnóstico do estágio atual da linha de ação 6, na UNITAU.

Legendas para o status: ___ aceitável; _ parcialmente aceitável; _ inexistente.

\section{LINHA DE AÇÃO 7: MAIOR ENVOLVIMENTO DOS ESTUDANTES}

A participação dos estudantes na gestão organizacional é uma necessidade, quer por meio da Associação de Estudantes, quer por meio dos representantes de alunos nos Conselhos Pedagógicos e Conselhos Disciplinares de cada curso.

Na UNITAU, existe o Diretório Central dos Estudantes - DCE, cujo estatuto foi aprovado em 2010 (DELIBERAÇÃO CONSUNI No 041/2010).

O Quadro 6 apresenta um resumo da linha de ação sete, na IES.

\begin{tabular}{|l|l|l|}
\hline Linha de ação 7 & \multicolumn{2}{|l|}{ status observações } \\
ítem avaliado & & DCE \\
\hline Existência de uma Associação de Estudantes & & pouco evidente \\
Participação dos estudantes na promoção interna da qualidade & & INIC etc. \\
\hline Participação estudantil em projetos científicos & & \\
\hline
\end{tabular}

Quadro 6 - diagnóstico do estágio atual da linha de ação 7, na UNITAU.

Legendas para o status: ___ aceitável; _ parcialmente aceitável; _ _ inexistente.

Revista Ibero-Americana de Estratégia - RIAE, São Paulo, v. 11, n. 3, p. 263-288, set./dez. 2012. 
Adoção de Procedimentos Internacionais, do Processo de Bolonha, por uma Universidade Nacional: Um Estudo de Caso

\section{DISCUSSÕES}

O Processo de Bolonha oferece perspectivas contemporâneas para qualquer IES brasileira que almeje a internacionalização. A transparência e a disponibilidade de informação preconizadas pelo EEES (BOLONHA, 2010) permitem que uma instituição possa identificar o estado da arte em relação à educação superior. Não existe o caminho certo. Tampouco uma receita única para que uma IES possa estar em sintonia com as demais instituições em um nível global.

O estudo realizado na Universidade de Taubaté, particularmente no curso de Administração, permite identificar o estágio atual da Instituição nas linhas de ação propostas pelo modelo europeu, que estão ao alcance da Instituição.

A adequação aos três ciclos propostos (bacharelado, mestrado e doutorado) depende da criação do curso de doutorado, que já faz parte da estratégia da Instituição.

O principal desafio, no entanto, não está na adequação aos três ciclos propostos pelo Processo de Bolonha. Afinal, no Brasil, o ensino superior já está dividido em graduação, mestrado e doutorado.

A dificuldade está no modelo proposto que é centrado no aluno, ou seja, no aprendizado, em vez de no ensino; no desenvolvimento de competências por parte dos alunos. Para Camargo e Maués (2008, p. 228), “(...) a crítica ao modelo de currículo centrado no ensino por disciplinas, ainda predominante nos dias atuais, é um aspecto igualmente importante na chamada pedagogia das competências". A lógica de tal proposta é que "o ensino disciplinar não consegue dar conta das necessidades hoje postas".

Atualmente, os cursos de graduação, na UNITAU, ainda funcionam, em grande parte, anualmente e no formato disciplinar, incluindo, aí, o curso de Administração. A mudança para semestral já foi testada e entrará em vigor a partir de 2013. E o desenvolvimento de competências, que faz parte das Diretrizes Curriculares Nacionais do curso (BRASIL, 2005), não está evidente no projeto pedagógico.

A dificuldade encontrada para a implementação de uma mudança institucional, seja esta curricular ou não, é um entrave que precisa ser superado caso a instituição busque excelência em nível internacional.

Superar esse entrave é um grande desafio, porém necessário, caso a instituição pretenda formar mão de obra qualificada para as novas necessidades do mercado de trabalho. Importante, no entanto, é que haja a participação de todos os envolvidos em todo o processo, assim como é preconizado no Processo de Bolonha.

Revista Ibero-Americana de Estratégia - RIAE, São Paulo, v. 11, n. 3, p. 263-288, set./dez. 2012. 
Edson Aparecida de Araujo Querido Oliveira, Leonardo de Almeida Teixeira \& Elvira Aparecida Simões de Araujo

Considerando-se o estágio atual em que se encontram os cursos de administração na Universidade de Taubaté, aparenta mais plausível que as mudanças iniciem-se pelo curso de mestrado. Morosini (2008) relata que devido à sua natureza de produção de conhecimento, a universidade sempre teve como norma a internacionalização da função pesquisa. A autora afirma que (p. 302) “a internacionalização da educação superior é mais ágil e mais rápida na função acadêmica de pesquisa".

A adequação do sistema de créditos, de modo que este respeite as diretrizes apontadas pelos ECTS, demanda a participação direta dos docentes, sempre com base nas necessidades apresentadas pelo mercado de trabalho. A definição de unidade curricular, em vez de disciplina, aponta a necessidade do desenvolvimento de competências.

Espera-se que, ao concluir uma unidade curricular, o aluno desenvolva uma competência. Atualmente, a aprovação em uma determinada disciplina não indica que houve aprendizado. As atividades não formais e informais desenvolvidas pelos alunos não são consideradas. Alunos que cursam idiomas e/ou informática, entre outras atividades que podem ser aplicadas, por intermédio, ou não, de empresas empregadoras, não possuem essas atividades reconhecidas. No Processo de Bolonha, elas passam a ter valor, desde que comprovado o aprendizado. (BOLONHA, 2010)

As competências desenvolvidas em atividades não formais ou informais estão relacionadas ao perfil de cada aluno. E o objetivo é justamente habilitar o estudante para que este esteja apto para se empregar, manter-se empregado e circular no mercado de trabalho.

Para isso, as atividades extracurriculares precisam ser valorizadas, afinal, o dinamismo do mercado de trabalho exige a pró-atividade por parte do profissional, e impede que se consiga delimitar, em um curso, todas as competências exigidas para atuar com êxito no mercado de trabalho.

A mobilidade acadêmica já é uma realidade na UNITAU. Existem programas de intercâmbio em nível de graduação. A adequação às diretrizes apresentadas no Processo de Bolonha podem contribuir para que essa mobilidade aumente ainda mais. Tanto no que diz respeito aos alunos de graduação, como para os alunos de mestrado, professores e demais profissionais da Instituição.

A possibilidade de começar a implantação do modelo pelo segundo ciclo pode facilitar ainda mais essa mobilidade. Afinal, trata-se de um número menor de alunos e professores, além de servir como um estímulo para a mobilidade de professores e pós-graduandos que ainda não pertencem a nenhum programa de mobilidade realizado pela Instituição.

Revista Ibero-Americana de Estratégia - RIAE, São Paulo, v. 11, n. 3, p. 263-288, set./dez. 2012. 
Adoção de Procedimentos Internacionais, do Processo de Bolonha, por uma Universidade Nacional: Um Estudo de Caso

A garantia de qualidade é um dos principais temas apresentados no modelo europeu. Por se tratar de uma Autarquia Municipal, a transparência, com relação ao uso dos recursos, já existe na UNITAU.

No entanto, a qualidade precisa ser entendida como algo percebido pelos stakeholders e em constante evolução. Isso significa que algumas ferramentas precisam ser introduzidas internamente para mensurar o nível de qualidade percebida pelos envolvidos no processo.

Agências externas, acreditadas para atuar no EEES, podem auxiliar no direcionamento dos esforços da Instituição no que se refere à qualidade do ensino superior. A autonomia da Instituição não pode ser abalada, mas a abertura às novas realidades que estão em constante evolução, demonstra que a Instituição não está abrindo mão de seu poder, e, sim, permitindo que agentes internacionais colaborem para a melhoria contínua dos serviços ofertados pela IES.

A UNITAU está inscrita no programa promovido pelo governo federal, "Ciência sem Fronteiras". Com isso, a Universidade assume o compromisso da validação dos créditos obtidos pelos seus estudantes de graduação, no exterior.

A adequação às diretrizes propostas pelo modelo europeu pode permitir a consolidação de alianças de exploração, que, conforme Peng e Pleggenkuhle-Miles (2009), propiciam uma experiência única de aprendizado, de modo que a Instituição possa ter acesso ao conhecimento tácito dos parceiros, e avaliar o seu valor intrínseco.

Isso converge às contribuições da evolução do modelo de Uppsala (JOHANSON; VAHLNE, 2009), no qual se ressalta a importância da estrutura de network fora da rede de relacionamentos de negócios da empresa e a estrutura relevante em mercados estrangeiros.

Destaca-se, por fim, que, para aumentar a possibilidade de sucesso na implantação de qualquer melhoria interna, torna-se essencial a participação efetiva de todos os envolvidos, incluindo, nesse contexto, professores, alunos, pessoal administrativo e demais interessados, visto que, conforme sugerem Hofstede et al. (2002), as instituições são a cristalização da cultura e a cultura é o substrato dos arranjos institucionais.

\section{CONCLUSÕES}

A internacionalização das IES pode ser considerada um fenômeno recente no Brasil. Poucas são as instituições que incorporaram o desenvolvimento da atuação, em um nível internacional, em suas estratégias organizacionais.

Revista Ibero-Americana de Estratégia - RIAE, São Paulo, v. 11, n. 3, p. 263-288, set./dez. 2012. 
Edson Aparecida de Araujo Querido Oliveira, Leonardo de Almeida Teixeira \& Elvira Aparecida Simões de Araujo

O próprio Processo de Bolonha é um fenômeno recente. Afinal, são pouco mais de dez anos desde a assinatura da Declaração de Bolonha (1999), e pouco mais de cinco anos (BERGEN COMMUNIQUÉ, 2005) desde a implantação do modelo em instituições europeias.

Espelhar-se no modelo europeu significa poder estar em sintonia com o sistema de educação adotado em 47 países e aceito pelas principais economias do globo. Essa medida pode caracterizar uma fonte de vantagem competitiva para uma instituição brasileira.

A adoção de alguns parâmetros internacionais possibilita a criação de uma referência local, um benchmark em educação superior, em um país que desperta interesse global no cenário atual.

Adotar uma estratégia de internacionalização significa dar início a um processo de mudanças contínuas. O EEES, principal objetivo do Processo de Bolonha, está em constante desenvolvimento. Estreitar laços com instituições estrangeiras caracteriza o desenvolvimento de networks.

O Processo de Bolonha permitiu que as nações adeptas pudessem adequar as suas normas e legislações para promover a inserção institucional. No Brasil, as IES buscam referências na Lei de Diretrizes e Bases (LDB), que é desenvolvida pelo governo federal. Por isso, o presente estudo procurou apontar possíveis mudanças que podem ser implementadas em nível institucional, sem desrespeitar a legislação local.

Afinal, a autonomia institucional faz parte de um dos pressupostos do modelo europeu e da legislação brasileira (BOLONHA, 1999; BRASIL, 1996). Entrar nos méritos da LDB ou da atuação do Governo Federal na educação superior brasileira não está no escopo do presente trabalho.

A adoção do Processo de Bolonha por uma IES almeja uma maior legibilidade dos cursos, resultante da maior harmonização de designações, da explicitação dos resultados da aprendizagem, ou da adoção do sistema ECTS. Isso permite o fácil reconhecimento e transferência de formações realizadas, reforçando a mobilidade nacional e internacional de estudantes.

Logicamente que, além de mudanças em nível de docentes, esperam-se mudanças em nível de estudantes. Vários discentes vivenciam uma ruptura nas suas atitudes e práticas de estudo na transição para o Ensino Superior - que se agrava ainda mais com o Processo de Bolonha - o que tendencialmente obriga um maior "diálogo" entre o Ensino Secundário e a Educação Superior.

A concretização de Bolonha envolve a preparação dos docentes e estudantes, para as mudanças pedagógicas, por meio da oferta generalizada de ações de formação. Para os docentes, as ações incluem os métodos ativos de ensino e aprendizagem, a avaliação contínua ou a facilitação da relação professor-estudante.

Revista Ibero-Americana de Estratégia - RIAE, São Paulo, v. 11, n. 3, p. 263-288, set./dez. 2012. 
Adoção de Procedimentos Internacionais, do Processo de Bolonha, por uma Universidade Nacional: Um Estudo de Caso

Para os estudantes, a necessidade do desenvolvimento de um programa destinado aos calouros, visando ao desenvolvimento de competências para uma aprendizagem mais autônoma e na perspectiva de construção de conhecimento. Importante, também, acrescentar ações de formação específicas dirigidas aos Diretores de Curso e aos representantes estudantis, operacionalizando as suas funções, com base nas exigências do Processo de Bolonha.

A implementação de Bolonha tem seus custos. Além do envolvimento exigido aos agentes (docentes, estudantes e gestores dos projetos de ensino) e às instituições, importaria que o financiamento do Ensino Superior facultasse os meios necessários à mudança e objetivos almejados.

O presente trabalho não pretendeu apresentar uma solução para algum problema enfrentado por uma IES brasileira. Tampouco, abordou particularidades enfrentadas junto aos órgãos de classe locais, ou questionou os princípios neoliberais que, segundo alguns críticos, orientam as reformas do ensino superior no presente século (SGUISSARDI, 2008; DIAS SOBRINHO, 2010).

No entanto, demonstra que as diretrizes do modelo europeu, o Processo de Bolonha, convergem para os demais sistemas de educação superior na atualidade, uma vez que procura atender às exigências do mercado. Mais do que isso, serve como referência a qualquer sistema de Educação Superior. (LIMA et al., 2008)

Afinal, as novas exigências demandam novas metodologias para a formação dos profissionais. Profissionais esses que podem ter nascido em um período em que o acesso à informação era restrito, necessitando, portanto, da educação continuada, ou mesmo em um momento no qual a informação se tornou uma simples commodity, a que todos têm acesso. O fato é que a internacionalização propicia o fortalecimento das redes de relacionamento. E o modelo de Bolonha é um dos caminhos para isso.

Revista Ibero-Americana de Estratégia - RIAE, São Paulo, v. 11, n. 3, p. 263-288, set./dez. 2012. 
Edson Aparecida de Araujo Querido Oliveira, Leonardo de Almeida Teixeira \& Elvira Aparecida

Simões de Araujo

\section{REFERÊNCIAS}

Altbach, P.G. Globalization and the university: Realities in an unequal world. J.J.F. Forest and P.G. Altbach (eds.), International Handbook of Higher Education, Vol. 1. Dordrecht, The Netherlands, Springer. 121-140. 2006.

Altbach, P.G.; Reisberg, L.; Rumbley, L.E. Trends in Global Higher Education: Tracking an Academic Revolution. A Report Prepared for the UNESCO 2009 World Conference on Higher Education. 2009.

Altbach, P. G; Knight, J. The Internationalization of Higher Education: Motivation and Realities. Journal Studies in International Education, vol. 11 No.3/4, Fall/Winter 2007. p. 290-305.

Araujo, L; Rezende, S. Path dependence, MNCs and the internationalisation process: a relational approach. International Business Review, v. 12, n. 6, p. 719-737, 2003.

Bolonha. Budapest-Vienna Declaration. Criação do Espaço Europeu de Educação Superior. UE. 2010.

Declaração do Processo de Bolonha. 1999.

Brasil. Resolução $\mathrm{n}^{\circ}$ 4, de 13 de julho de 2005. Institui as Diretrizes Curriculares Nacionais do Curso de Graduação em Administração, bacharelado, e dá outras providências. Conselho Nacional de Educação - Câmara de Educação Superior. Diário Oficial [da República Federativa do Brasil], Brasília, DF. 2005.

Lei n ${ }^{\circ}$ 9.394, de 20 de dezembro de 1996. Estabelece as diretrizes e bases da educação nacional. Diário Oficial [da República Federativa do Brasil], Brasília, DF. 1996.

Buckley, P. J.; Ghauri, P. N. Globalization, economic geography and the strategy of multinational enterprises. Journal of International Business Studies, v. 35, n. 2, p. 81-98, 2004.

Dias Sobrinho, J. Avaliação e Transformações da Educação Superior brasileira (1995-2009): do Provão ao SINAES. Avaliação (UNICAMP), v.15, p. 195-224, 2010.

. Sobre Reformas e Transformações da Educação Superior. Quaestio (UNISO), Sorocaba, v. 7, n. 1, p. 09-21, 2005.

Douglas, S.; Craig,C. Advances in International Marketing, International Journal of Research in Marketing, Vol. 9, n4, Dezembro, p.291-318. 1992.

Dunning, J.H. The Location of International Firms in an Enlarged EEC. An Exploratory Paper. Manchester: Manchester Statistical Society, 1972. 
Adoção de Procedimentos Internacionais, do Processo de Bolonha, por uma Universidade Nacional: Um Estudo de Caso

The Ecletic (OLI) Paradigm of International Production: Past, Present and Future, International Journal of the Economics of Business, Vol 8, n2, p.173-190, 2001.

ENQA. Standards and Guidelines for Quality Assurance in the European Higher Education Area 1st edition. 2005.

Hofstede, G.; Van Deusen, C.; Mueller, C.; Charles, T. What goals do business leaders pursue? A study in fifteen countries. Journal of International Business Studies, v. 33(4) p. 785-803. 2002.

. The Uppsala internationalization process model revisited: From liability of foreignness to liability of outsidership. Journal of International Business Studies, v. 40, p. 1411-1431, 2009.

Knight, J. Updating the definition of internationalization. International Higher Education Journal. v.33, n. 3, p. $2-3$, outono 2003.

Internationalization remodeled: definition, approaches and rationales. Journal of Studies in International Education. v. 8, n. 1, p. 5 - 31, 2004.

An internationalization model: responding to new realities and challenges. In: De Wit, H.; Jaramillo, I. C.; Garcel-Avila, J.; Knight, J. (Org.). Higher education in Latin America: the international dimension. Washington: World Bank, 2005.

Lima, L. C ; Azevedo, M. L. N. ; Catani, A. M. . O processo de Bolonha, a avaliação da educação superior e algumas considerações sobre a Universidade Nova. Avaliação (Campinas), v. 13, p. 736, 2008.

London Communiqué. Relatório da Conferência dos Ministros Europeus Responsáveis pela Educação Superior. 2007

Madsen, T. Managerial judgment of export performance. Journal of International Marketing, v. 6, n.3, p. 82-93, 1998.

Mancebo, D. Reforma da educação superior: o debate sobre a igualdade no acesso. In: Bittar, M.; Oliveira, J. F.; Morosini, M. (Org.). Educação superior no Brasil - 10 anos pós-LDB. Brasília: INEP, 2008, v. , p. 55-70.

Maués, O. C. A Educação na Contemporaneidade: mercantilização e privatização?. Universidade e Sociedade (Brasília), Brasília, v. XV, n. 37, p. 81-92, 2006.

Maués, O. C. ; Camargo, A. M. As Mudanças no Mundo do Trabalho e a Formação dos Profissionais da Educação no Contexto da LDB: o currículo em questão. In: Bittar, M.; Ooliveira, J. F.; Morosini, M. (Org.). Educação Superior no Brasil: 10 anos Pós-LDB. 234 ed. Brasília: INEP/MEC, 2008, v. 2, p. -215. 
Edson Aparecida de Araujo Querido Oliveira, Leonardo de Almeida Teixeira \& Elvira Aparecida Simões de Araujo

Miura, I. K. O processo de internacionalização da Universidade de São Paulo: um estudo de três áreas do conhecimento. Ribeirão Preto, 2006. 365f. Tese (Livre Docência em Administração) Faculdade de Economia, Administração de Ribeirão Preto. Universidade de São Paulo.

Morgado, J.C. Globalização e (re)organização do ensino superior: perplexidades e desafios. Perspectiva, Florianópolis, v. 24, n.1, p.205-228, jan/jun. 2006.

Morosini, M. C. Qualidade e Internacionalização da Educação Superior: Indicadores Preparado para apresentação no Congresso de 2010 da LASA (Associação de Estudos Latino-Americanos), no Toronto, Canadá, de 06 a 09 de outubro de 2010.

Internacionalização da Educação Superior no Brasil pós-LDB: o impacto das sociedades tecnologicamente avançadas. In: Bittar, M.; Oliveira, J. F.; Morosini, M. (Org.). Educação superior no Brasil - 10 anos pós-LDB. 1 ed. Brasília - DF, 2008, v. 2, p. 285-304.

Peng, M. Global Business. Cengage Learning. Second Edition. 2011.

Peng, M; Pleggenkuhle-Miles, E. Current Debates in Global Strategy. International Journal of Management Reviews. v.11 I 1 pp.51-68, 2009.

Peng,M; Wang,D; Sun,S; Pleggenkuhle-Miles, E. A Unified Framework for International Business, Jan 2009.

Porter, M. Competitive strategy: techniques for analyzing industries and competitors. New York: The Free Press, 1980.

. What is Strategy? Harvard Business Review. Nov-Dec 1996.

Prahalad, C.K.; Conner, K. A resource-based view of the firm: knowledge versus opportunism. Organization Science. V. 35, n. 5, p. 477-501, 1996.

Quintanilha, A. Cruzamento de saberes: aprendizagens sustentáveis. Lisboa: Fundação Calouste Gulbenkian, 2003. p.23-33.

Sguissardi, V. Modelo de Expansão da Educação Superior no Brasil: predomínio privado/mercantil e desafios para a regulação e a formação universitária. Educação e Sociedade, v. 29/105, p. 9911022, 2008a.

. Educação Superior no limiar do novo século: traços internacionais e marcas domésticas. In: Zainko, M. A.; Gisi, M. L. (Org.). Políticas e Gestão da Educação Superior. 1 ed. Curitiba, PR; Florinópolis, SC: Champagnat; Insular, 2003, v. 1, p. 195-222.

Revista Ibero-Americana de Estratégia - RIAE, São Paulo, v. 11, n. 3, p. 263-288, set./dez. 2012. 
Adoção de Procedimentos Internacionais, do Processo de Bolonha, por uma Universidade Nacional: Um Estudo de Caso

Stallivieri, L. Estratégias de Internacionalização das Universidades brasileiras. Caxias do Sul: Educs, 2004. 143 p.: il.; 22 cm. (coleção internacional)

Vergara, S. C. Métodos de pesquisa em administração. São Paulo: Atlas, 2005.

Welch, L.; Luostarinen, R. Internationalization: evolution of a concept. Journal of General Management, v. 14, n.2, p. 34-55, 1988.

Recebido: 23/04/2012

Aprovado: 28/06/2012

Revista Ibero-Americana de Estratégia - RIAE, São Paulo, v. 11, n. 3, p. 263-288, set./dez. 2012. 